\title{
Comparative Evaluation of Fuzzy Axiomatic Design and IAMS Comprehensive VIKOR Approaches for Material Selection in Mechanical Design
}

\author{
Filippo Ceccanti ${ }^{1}$, Alessandro Giorgetti ${ }^{1}$, Carlo Cavallini $^{2}$, Gabriele Arcidiacono ${ }^{1}$, and Paolo Citti ${ }^{1}$ \\ ${ }^{1}$ Department of Innovation and Information Engineering, Guglielmo Marconi University, Via Plinio 44-00193 Rome, Italy.
}

${ }^{2}$ GKN Driveline Spa, Via Fratelli Cervi, 1, 50013, Campi Bisenzio, Italy.

\begin{abstract}
ORCIDs: 0000-0001-7317-873X (Filippo Ceccanti), 0000-0002-8232-1523 (Alessandro Giorgetti) 0000-0003-3365-4249 (Carlo Cavallini), 0000-0002-7712-1009 (Gabriele Arcidiacono) 0000-0002-3066-5105 (Paolo Citti)
\end{abstract}

\begin{abstract}
In the mechanical design, the selection among material alternatives has become a pressing issue due to the progressive growth in the complexity of mechanical systems, in search of continuous increase in performance and the presence of a wide range of possible materials. Moreover, there are many requests for projects, and this makes the choice of material a decisive activity for the success or failure of the project itself. This paper makes a comparative evaluation of two important approaches to identify the best materials alternatives: the C-VIKOR and the Fuzzy Axiomatic Design. The work considers as a case study the selection of the material for the production of the valve seats in a highperformance engine. An evaluation of the results obtained is made to show the peculiarity of each of the two approaches.
\end{abstract}

Keywords: material selection, Axiomatic Design, MADM, mechanical components, design methods, coating, highperformance engine.

\section{INTRODUCTION}

Within the industrial environment, the continuous introduction of new materials makes their choice harder and harder. In particular, the material selection discipline needs to be continuously updated and reviewed to know what is the viable algorithm to be considered in any circumstance.

One of the most critical issues is the correct choice of the "selection attributes" because it demands the exact translation of the customer needs into the technical requirements and the attribution of an importance weight to each of them ([1, 2]). In fact, the design team should use these attributes to evaluate the best among a number of possible alternatives for the design. The data about the performance of each of the candidate materials can be obtained by a wide range of sources such as on-line databases, handbooks, datasheet from Suppliers, experimental data, etc. The Multi-Attribute Decision Making (MADM) algorithms are based on the use of this information, the selection attributes and the importance weight of each of them to calculate the ranking of each design alternatives.

A previous work of the authors has developed a model, called Integral Aided Material Selection (IAMS) [3], that use House of Quality approach and one of the reliable MADM algorithm (i.e., the Comprehensive VIKOR algorithm or C-VIKOR [4, 5]). The IAMS method is a good selection process from the translation of the customer needs into the technical requirements and then to obtain the ranking of the design alternatives.

One alternative approach to obtain the ranking of the design alternative is based on Axiomatic Design (i.e., a structured method to identify optimal solution applied in a wide range of scientific and industrial environment [6-11]). Using this method, some specific approaches for MADM algorithm have been developed. In this paper we will consider, in particular, Intuitionistic Fuzzy Axiomatic Design (FAD) and Intuitionistic Weighed Fuzzy Axiomatic Design (WFAD) [1216].

This work aims to evaluate how two different material selection algorithms behave with respect to the same case study. In particular, the original C-VIKOR results [17] will be compared with the results obtained by the use of Intuitionistic Fuzzy Axiomatic Design (FAD and WFAD).

\section{THE MATERIALS AND METHODS}

As stated in the previous section, this work aims to compare material selection results coming from two different algorithms. Figure 1 shows the logical path to obtain the ranking of the materials when using the two algorithms (IASM-C-VIKOR and FAD-WFAD). The first algorithm considered is C-VIKOR. This algorithm will be considered as a sort of benchmark in this work since its application for the material selection of this case study has been already carried out by [17].

Briefly, the material selection based on the C-VIKOR algorithm is structured in the following steps:

- Definition of the weight of each factor through the generation of a House of Quality (HoQ);

- Then, considering the attributes weight, the C-VIKOR algorithm is applied.

The second algorithm considered, on the contrary, is based on the use of Fuzzy Axiomatic Design, both unweighted (FAD) and weighted (WFAD) [12-15]. The application of this algorithm will be detailed explained in the following of the work. 
IAMS - C VIKOR approach

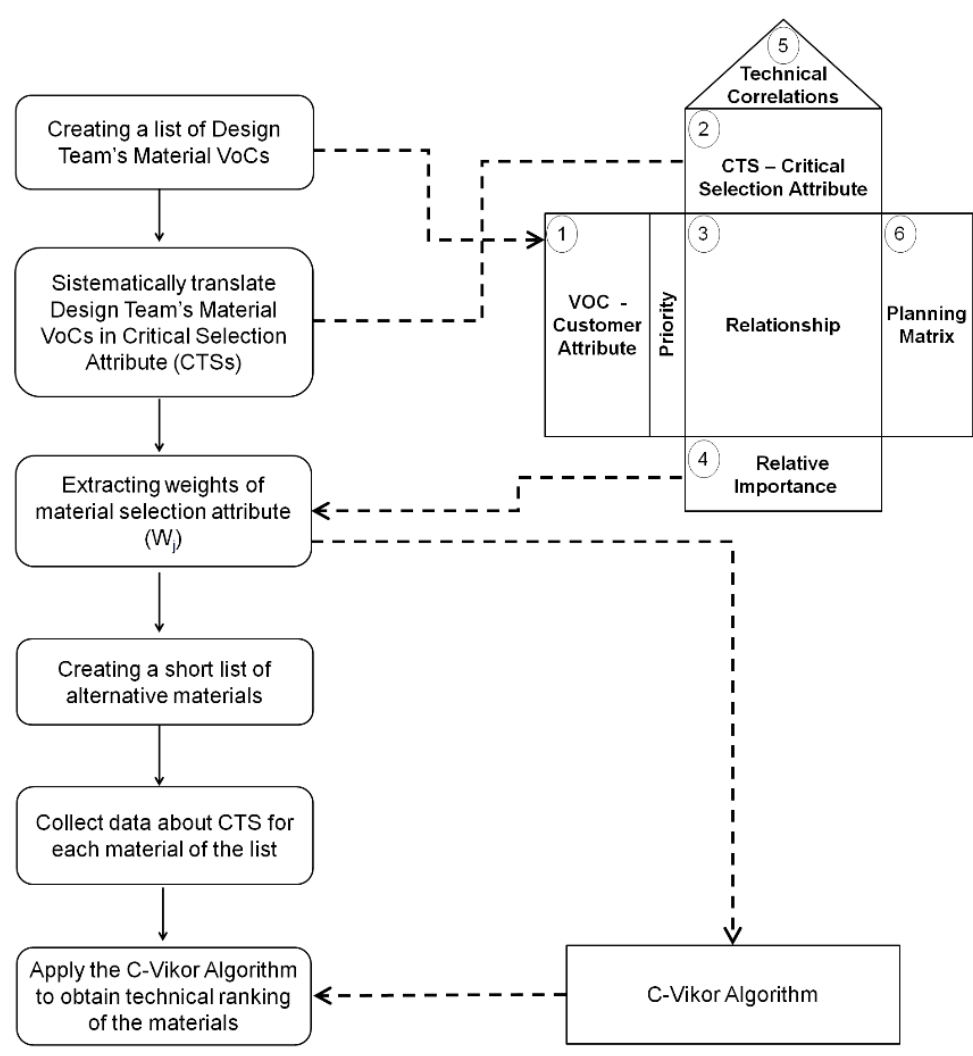

\section{Fuzzy Axiomatic Design FAD, WFAD approach}

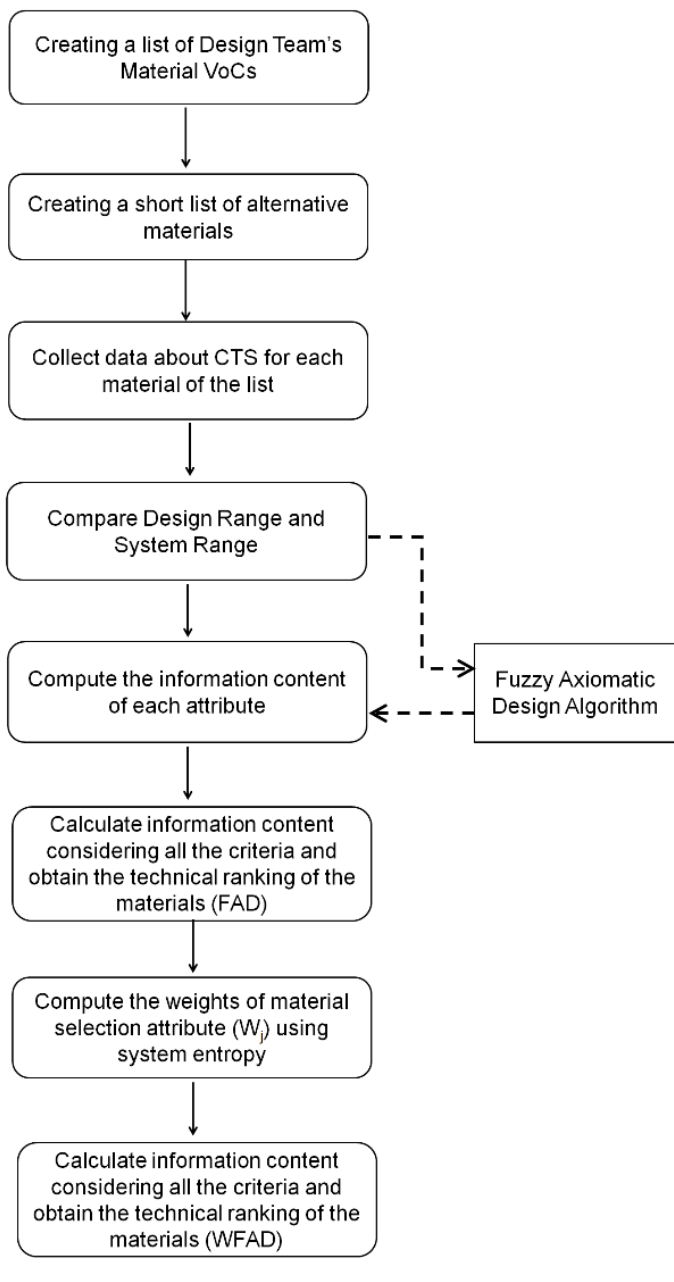

Fig 1. Comparison between the logical path to obtain the ranking of the materials when using the two algorithms.

From a methodologic perspective, the use of the Fuzzy Axiomatic Design requires less calculation to get the final ranking. For each attribute, a design range is defined by the specification itself. To manage uncertainty, fuzzy logic can be used. In particular, it is possible to choose between triangular, rectangular, and trapezoidal distribution to manage specification uncertainty. For each element considered (in the case study each material), the system range for each attribute shall be defined as well. Even in this case, fuzzy logic can be adopted to manage uncertainty.

Then, by the comparison of design range and common range, the probability of success is calculated. Basing on this information, the Fuzzy Axiomatic Design allows defining an overall parameter suitable to identify the best choice for the considered application. In case of the will to consider even the weight of each parameter, the Fuzzy Axiomatic Design allows us to include it through the evaluation of the system entropy.

The process followed using the Fuzzy Axiomatic Design is quite similar to the one used with the C-VIKOR algorithm, but there is no need to extract the weight of each attribute. In addition, the list of material can be obtained even without the use of the HoQ, simplifying the process and deriving the weights directly from quantitative information.

Specifically:

- Define the scope of the work collecting the Voice of Customer (VOC) [18-20];

- Create a list of candidates for project satisfaction;

- Collect all the required technical data for the evaluation of each candidate from all the considered perspectives [21];

- Compare, for each attribute design range, and system range, evaluating how each candidate can satisfy each specific attribute;

- By using the Fuzzy Axiomatic Design algorithm, data coming from the design and system range comparison are elaborated to obtain a value that represents how each 
attribute is satisfied by each candidate (the lower the number, the better). This value is called information content; there will be as many values as many attributes considered;

- Summing all the information contents, it is possible to calculate the overall information content that can be used to make the final ranking (even in this case, the lower the information content is, the better).

The Fuzzy Axiomatic Design algorithm, as stated above, is based on two main aspects:

- Possibility to manage uncertainty by the use of fuzzy distributions (triangular or trapezoidal);

- Comparison of design range (specification) and system range (candidate) to calculate the probability to satisfy the attribute.

For the case study considered in the following, characteristics have been subdivided into two main categories: data and attributes.

For data characteristics, such as thermal conductivity and Young modulus, design range and system range have been considered as a rectangle, since commonly specifications indicate just a range (and not a distribution).

For attribute characteristics, on the contrary, triangular distributions have been considered for the calculations. Since the design range, in all the cases, is a "larger the-better", asymmetric triangles have been considered. For system range, on the contrary, symmetric triangles centered on the score have been used.

To evaluate what is the best material for the considered application, the information content has been assessed using both the FAD and WFAD approaches [12-15].

Basing on these assumptions, we proceeded to compute the common range as the intersection between design range and system range.

With this data, it is possible to compute the information content of each attribute of each material with the probability of success, assessed as:

$$
\begin{array}{r}
p_{i, j}=\frac{\text { common range }}{\text { system range }} \\
I_{i, j}=-\log _{2} \frac{1}{p_{i, j}}
\end{array}
$$

Where $i$ is the $i$-th material (thus, the $i$-th row) and $j$ is the $j$-th attribute of the $\mathrm{i}$-th material (thus the $\mathrm{j}$-th column).

By summing the information content related to all the attribute of each material, it is possible to calculate the information content related to the considered material (3):

$$
I_{i}^{F A D}=\sum_{j} I_{i, j}
$$

This is the algorithm followed to assess the FAD parameter for each material.

As stated in the previous section, also the WFAD parameter has been considered within this work.
With respect to the FAD, the WFAD approach allows us to include in the information content evaluation a weight, to differentiate attribute importance.

To assess the weight, for each attribute of each material, the average value shall be assessed (since we considered the rectangular and triangular design and system ranges). The parameter obtained by this step is called $x_{i, j}$.

At this point, each $x_{i, j}$ shall be normalized (4):

$$
f_{i, j}=\frac{x_{i, j}}{\sum_{i} x_{i, j}}
$$

With this data, the system entropy and its weight coefficient can be calculated using (5) and (6):

$$
\begin{gathered}
E_{j}=-\frac{1}{\ln n} \sum_{i} f_{i} \ln f_{i} \\
w_{j}=\frac{1-E_{j}}{\sum_{j}\left(1-E_{j}\right)}
\end{gathered}
$$

where $\mathrm{n}$ is the number of rows (thus the number of materials considered).

It is important to note that with these expressions, a coefficient for each attribute will be assessed.

Once the weight and the system entropy values have been determined, the information content related to each attribute of each material can be assessed with (7):

$$
I_{i j}=\left\{\begin{array}{l}
{\left[\log _{2}\left(\frac{1}{p_{i j}}\right)\right]^{\frac{1}{w_{j}}}, 0 \leq I_{i j}<1} \\
{\left[\log _{2}\left(\frac{1}{p_{i j}}\right)\right]^{w_{j}}, \quad I_{i j}>1} \\
w_{j}, \quad I_{i j}>1
\end{array}\right.
$$

As in the previous case, the global WFAD parameter for each material can be calculated as the sum of all the information content related to all the attributes of the considered material (8).

$$
I_{i}^{W F A D}=\sum_{j} I_{i, j}
$$

This parameter can then been used to obtain a ranking among the various solutions.

\section{CASE STUDY}

As previously stated, in this paper, the comparison between the results obtained by the application of two different algorithms for the material selection of a case study is carried out. The case study consists of the choice of the coating for the valve seats of a high-performance engine (Figure 2).

Valve seats are a critical component of a combustion chamber since it needs to carry out two main functions.

- Guarantee the chamber tightness ensuring the contact with the valve;

- Dissipate the heats absorbed by the valve, allowing the 
engine to work at higher temperatures and increasing the thermodynamic efficiency.

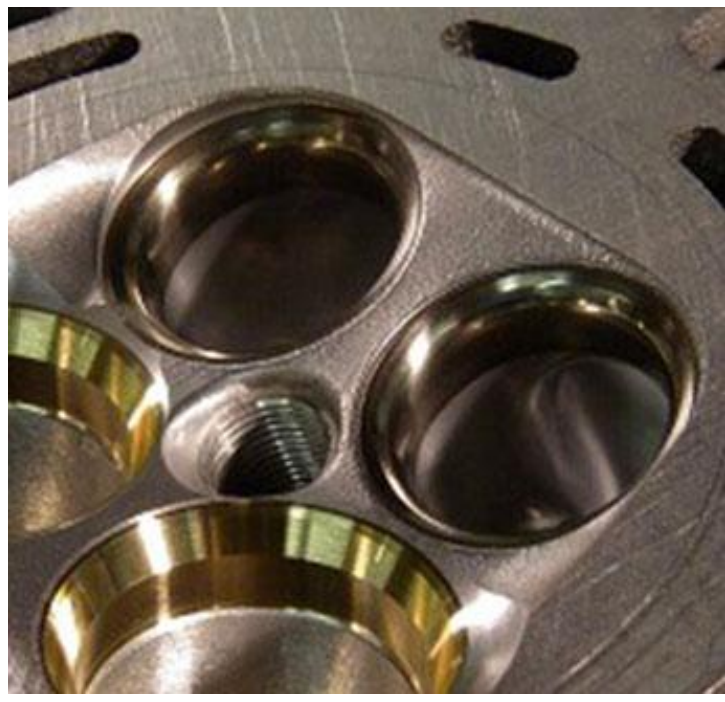

Fig 2. Example of valve seats of a high-performance engine.

Since the more recent high-performance engines come with aluminum structures (to allow an important mass reduction), the necessity to choose the right material for the valve seats is fundamental for the engine life. Aluminum, in fact, is not able to withstand thermo-mechanical stresses produced by the engine working; therefore it is essential to realize the considered component in a different material. Materials evaluated in this paper and the attribute value are listed in Table 1. The critical direction of improvement has been defined as Larger-The-Better (LTB), attributes that require a target value (Target), and Smaller-The-Better (STB).

Before to move on, an explanation of how data that are not affected by uncertainty have been used is necessary. Since the Fuzzy Axiomatic Design approach is based on the probability of success evaluation, exact data are not processable with this kind of approach. In fact, the probability computed as per above for an attribute expressed by a single value is always zero (since the associate range is 0 ), regardless of the position with respect to the design range. Therefore, to make the Fuzzy Axiomatic Design approach applicable to these data (enabling a direct result comparison), exact data have been translated is small ranges $( \pm 5 \%$ in most of the cases, for the hardness $\pm 0.8 \%)$.

Table 1. Completed selection matrix.

\begin{tabular}{|c|c|c|c|c|c|c|c|c|c|c|c|c|c|c|c|c|c|c|c|c|}
\hline & \multicolumn{2}{|c|}{$\begin{array}{c}\mathbf{K} \\
{[\mathrm{W} / \mathrm{mK}]}\end{array}$} & \multicolumn{2}{|c|}{$\begin{array}{c}\text { TEC } \\
{\left[10^{-6} / \mathrm{K}\right]}\end{array}$} & \multicolumn{2}{|c|}{$\begin{array}{c}\mathbf{E} \\
{[\mathrm{GPa}]}\end{array}$} & \multicolumn{2}{|c|}{$\begin{array}{c}\text { Hardness } \\
{[\mathrm{HV}]}\end{array}$} & \multicolumn{2}{|c|}{$\begin{array}{c}\text { Abrasion } \\
\text { Resistance } \\
\text { [null] }\end{array}$} & \multicolumn{2}{|c|}{$\begin{array}{c}\text { Hot } \\
\text { corrosion } \\
\text { resistance } \\
\text { [null] }\end{array}$} & \multicolumn{2}{|c|}{$\begin{array}{c}\text { Rupture } \\
\text { strength } \\
{[\mathrm{MPa}]}\end{array}$} & \multicolumn{2}{|c|}{$\begin{array}{l}\text { Density } \\
{\left[\mathrm{g} / \mathrm{cm}^{3}\right]}\end{array}$} & \multicolumn{2}{|c|}{$\underset{\text { [null] }}{\text { Machinability }}$} & \multicolumn{2}{|c|}{$\begin{array}{c}\text { Cost } \\
{[€ / \mathrm{kg}]}\end{array}$} \\
\hline $\begin{array}{c}\text { Optimization } \\
\text { type }\end{array}$ & \multicolumn{2}{|c|}{ LTB } & \multicolumn{2}{|c|}{ Target } & \multicolumn{2}{|c|}{ Target } & \multicolumn{2}{|c|}{ Target } & \multicolumn{2}{|c|}{ LTB } & \multicolumn{2}{|c|}{ LTB } & \multicolumn{2}{|c|}{ LTB } & \multicolumn{2}{|c|}{ STB } & \multicolumn{2}{|c|}{ LTB } & \multicolumn{2}{|c|}{ LTB } \\
\hline Best Value & & & & 22 & & 80 & & 70 & & 5 & & 5 & 5 & 5 & & & & 5 & & \\
\hline Materials & $\min$ & MAX & $\min$ & MAX & $\min$ & MAX & $\min$ & MAX & $\min$ & MAX & $\min$ & MAX & $\min$ & MAX & $\min$ & MAX & $\min$ & MAX & $\min$ & MAX \\
\hline 1. $\mathrm{CuBe}$ & 105 & 118 & 16.7 & 17 & 130 & 132 & 318 & 382 & 4 & 4 & 2 & 3 & 1030 & 1310 & 8.26 & 8.41 & 4 & 4 & 20.8 & 25.2 \\
\hline 2. $\mathrm{CuBe} 2$ & 105 & 130 & 16.7 & 17 & 131 & 134 & 353 & 413 & 4 & 5 & 2 & 3 & 1140 & 1380 & 8.25 & 8.36 & 5 & 5 & 23.5 & 25.9 \\
\hline 3. Alloy 3 & 240 & 240 & 17.6 & 17.6 & 138 & 138 & 195 & 250 & 2 & 3 & 3 & 3 & 690 & 900 & 8.83 & 8.83 & 3 & 4 & 21.9 & 24.1 \\
\hline 4. Alloy $310_{2}$ & 235 & 235 & 17.6 & 17.6 & 135 & 135 & 234 & 260 & 2 & 3 & 3 & 3 & 720 & 820 & 8.8 & 8.8 & 3 & 4 & 22.5 & 23.6 \\
\hline 5. C18150 & 280 & 324 & 17 & 17 & 117 & 120 & 130 & 155 & 1 & 2 & 2 & 2 & 380 & 520 & 8.89 & 8.9 & 4 & 5 & 7.6 & 7.84 \\
\hline 6. $\mathrm{C} 18000$ & 185 & 225 & 16.2 & 17.5 & 114 & 130 & 185 & 195 & 2 & 2 & 2 & 3 & 585 & 605 & 8.75 & 8.84 & 4 & 4 & 8.73 & 10 \\
\hline 7. SS 410 & 24.9 & 24.9 & 9.9 & 9.9 & 200 & 200 & 339 & 410 & 4 & 5 & 5 & 5 & 985 & 1310 & 7.74 & 7.8 & 1 & 2 & 1 & 13 \\
\hline 8. $50 \mathrm{CrV} 4$ & 46.6 & 46.6 & 12.2 & 12.2 & 205 & 205 & 309 & 350 & 4 & 5 & 3 & 4 & 1020 & 1145 & 7.83 & 7.85 & 2 & 3 & 0.7 & 0.8 \\
\hline 9. x38CrMoV51 & 18 & 21 & 11 & 11.8 & 207 & 215 & 551 & 632 & 5 & 5 & 3 & 4 & 1835 & 2100 & 7.8 & 7.8 & 2 & 3 & 4.24 & 5 \\
\hline
\end{tabular}


International Journal of Engineering Research and Technology. ISSN 0974-3154, Volume 13, Number 1 (2020), pp. 80-87

(C) International Research Publication House. https://dx.doi.org/10.37624/IJERT/13.1.2020.80-87

\section{RESULT}

Proceeding with the calculation as per above, we obtained the following results concerning the evaluation of the unweighted information content (Table 2) and the Ranking of solution technical optimality based considering FAD algorithm (Table $3)$.
For what concerns the weighted approach (WFAD), the probabilities are the same as in the previous case; the difference consists in considering weight factors calculated using (6). The results are reported in Table 4 and the ranking in Table 5.

The results obtained by the application of the C-VIKOR algorithm used as reference in this work [17] are listed in table 6 for comparison.

Table 2: Selection matrix with the value of the parameters $I^{\mathrm{FAD}}$.

\begin{tabular}{|c|c|c|c|c|c|c|c|c|c|c|c|}
\hline & $\mathbf{K}$ & $\begin{array}{c}\text { TEC } \\
{\left[10^{-6} /{ }^{\circ} \mathrm{C}\right]}\end{array}$ & $\begin{array}{c}\mathbf{E} \\
{[\mathrm{GPa}]}\end{array}$ & $\begin{array}{c}\text { Hardness } \\
{[\mathrm{HV}]}\end{array}$ & $\begin{array}{c}\text { Abrasion } \\
\text { Resistance } \\
\text { [null] }\end{array}$ & $\begin{array}{c}\text { Hot } \\
\text { corrosion } \\
\text { resistance } \\
\text { [null] }\end{array}$ & $\begin{array}{c}\text { Rupture } \\
\text { strength } \\
{[\mathrm{MPa}]}\end{array}$ & $\begin{array}{l}\text { Density } \\
{\left[\mathrm{kg} / \mathrm{m}^{3}\right]}\end{array}$ & $\begin{array}{c}\text { Machinability } \\
\text { [null] }\end{array}$ & $\begin{array}{c}\text { Cost } \\
{[€ / \mathrm{kg}]}\end{array}$ & \\
\hline System Range & 160 & 13 & 90 & 120 & 2.5 & 2.5 & 1150 & 2 & 2.5 & 25 & \\
\hline Material & p & $\mathbf{p}$ & $\mathbf{p}$ & $\mathbf{p}$ & $\mathbf{P}$ & $\mathbf{p}$ & $\mathbf{p}$ & $\mathbf{p}$ & $\mathbf{p}$ & p & $\mathbf{I}^{\mathrm{FAD}}$ \\
\hline 1. $\mathrm{CuBe}$ & 1 & 1 & 1 & 0.66 & 0.78 & 0.08 & 1 & 1 & 0.78 & 1 & 4.89 \\
\hline 2. $\mathrm{CuBe} 2$ & 1 & 1 & 1 & 0.12 & 0.92 & 0.08 & 1 & 1 & 1.96 & 0.625 & 6.49 \\
\hline 3. Alloy 3 & 1 & 1 & 1 & 0.18 & 0.08 & 0.28 & 1 & 1 & 0.56 & 1 & 8.71 \\
\hline 4. Alloy $310_{2}$ & 1 & 1 & 1 & 0.77 & 0.08 & 0.28 & 1 & 1 & 0.56 & 1 & 6.63 \\
\hline 5. $\mathrm{C} 18150$ & 0 & 1 & 1 & 0 & 0 & 0 & 0 & 1 & 0.92 & 1 & $+\infty$ \\
\hline 6. $\mathrm{C} 18000$ & 1 & 1 & 1 & 0 & 0 & 0.08 & 0 & 1 & 0.78 & 1 & $+\infty$ \\
\hline 7. SS 410 & 0 & 0 & 0.5 & 0.30 & 0.92 & 1.96 & 1 & 1 & 0 & 1 & $+\infty$ \\
\hline 8. $50 \mathrm{CrV} 4$ & 0 & 1 & 0.26 & 1.00 & 0.92 & 0.56 & 1 & 1 & 0.08 & 1 & $+\infty$ \\
\hline 9. $\mathrm{x} 38 \mathrm{CrMoV} 51$ & 0 & 0 & 0 & 0 & 1.96 & 0.56 & 0 & 1 & 0.08 & 1 & $+\infty$ \\
\hline
\end{tabular}

Table 3: Ranking of solution technical optimality based on FAD algorithm.

\begin{tabular}{clc}
\hline Place & \multicolumn{1}{c}{ Ranking based on IFAD } & I $^{\text {FAD }}$ \\
\hline & & STB \\
\hline $1^{\text {st }}$ & $\mathrm{CuBe}$ (Materion Alloy 165 temper TF00) & 4.89 \\
\hline $2^{\text {nd }}$ & $\mathrm{CuBe} 2$ & 6.49 \\
\hline $3^{\text {th }}$ & Alloy 310 (Materion Alloy 310 temper TF00) & 6.63 \\
\hline $4^{\text {th }}$ & Alloy 3 (Materion Alloy 3 temper TF00) & 8.71 \\
\hline N.A. & $\mathrm{C} 18150$ & $+\infty$ \\
\hline N.A. & $\mathrm{C} 18000$ & $+\infty$ \\
\hline N.A. & 50CrV4 (AISI 6150 steel oil quenched, 540 ${ }^{\circ} \mathrm{C}$ & $+\infty$ \\
\hline N.A. & SS 410 martensitic stainless steel & $+\infty$ \\
\hline N.A. & x38CrMoV51 (AISI Type H11) & $+\infty$ \\
\hline
\end{tabular}


International Journal of Engineering Research and Technology. ISSN 0974-3154, Volume 13, Number 1 (2020), pp. 80-87

(C) International Research Publication House. https://dx.doi.org/10.37624/IJERT/13.1.2020.80-87

Table 4: Selection matrix with the value of the parameters I ${ }^{\mathrm{WFAD}}$.

\begin{tabular}{|c|c|c|c|c|c|c|c|c|c|c|c|}
\hline & $\mathbf{K}$ & \begin{tabular}{|c|} 
TEC \\
{$\left[10^{-}\right.$} \\
$\left.6 /{ }^{\circ} \mathrm{C}\right]$ \\
\end{tabular} & $\begin{array}{c}\mathbf{E} \\
{[\mathrm{GPa}]}\end{array}$ & $\begin{array}{c}\text { Hardness } \\
{[\mathrm{HV}]}\end{array}$ & $\begin{array}{c}\text { Abrasion } \\
\text { Resistance } \\
\text { [null] }\end{array}$ & $\begin{array}{c}\text { Hot corrosion } \\
\text { resistance } \\
\text { [null] }\end{array}$ & $\begin{array}{c}\text { Rupture } \\
\text { strength } \\
{[\mathrm{MPa}]}\end{array}$ & $\begin{array}{l}\text { Density } \\
{\left[\mathrm{kg} / \mathrm{m}^{3}\right]}\end{array}$ & $\begin{array}{c}\text { Machinability } \\
{[\text { null }]}\end{array}$ & $\begin{array}{c}\text { Cost } \\
{[€ / \mathrm{kg}]}\end{array}$ & \\
\hline $\begin{array}{l}\text { System } \\
\text { Range }\end{array}$ & 160 & 13 & 90 & 120 & 2.5 & 2.5 & 1150 & 2 & 2.5 & 25 & \\
\hline $\mathbf{w}$ & 0.279 & 0.020 & 0.028 & 0.084 & 0.071 & 0.033 & 0.087 & 0.002 & 0.050 & 0.347 & \\
\hline Material & $\mathbf{p}$ & $\mathbf{p}$ & $\mathbf{p}$ & $\mathbf{p}$ & $\mathbf{p}$ & $\mathbf{P}$ & $\mathbf{p}$ & $\mathbf{p}$ & $\mathbf{p}$ & $\mathbf{p}$ & I WFAD $^{\text {WF }}$ \\
\hline 1. $\mathrm{CuBe}$ & 1 & 1 & 1 & 0.66 & 0.78 & 0.08 & 1 & 1 & 0.78 & 1 & 1.05 \\
\hline 2. $\mathrm{CuBe} 2$ & 1 & 1 & 1 & 0.12 & 0.92 & 0.08 & 1 & 1 & 1.96 & 0.625 & 2.52 \\
\hline 3. Alloy 3 & 1 & 1 & 1 & 0.18 & 0.08 & 0.28 & 1 & 1 & 0.56 & 1 & 3.22 \\
\hline 4. Alloy $310_{2}$ & 1 & 1 & 1 & 0.77 & 0.08 & 0.28 & 1 & 1 & 0.56 & 1 & 2.14 \\
\hline 5. C18150 & 0 & 1 & 1 & 0 & 0 & 0 & 0 & 1 & 0.92 & 1 & $+\infty$ \\
\hline 6. C18000 & 1 & 1 & 1 & 0 & 0 & 0.08 & 0 & 1 & 0.78 & 1 & $+\infty$ \\
\hline 7. SS 410 & 0 & 0 & 0.5 & 0.30 & 0.92 & 1.96 & 1 & 1 & 0 & 1 & $+\infty$ \\
\hline $8.50 \mathrm{CrV} 4$ & 0 & 1 & 0.26 & 1 & 0.92 & 0.56 & 1 & 1 & 0.08 & 1 & $+\infty$ \\
\hline $\begin{array}{c}9 . \\
\times 38 C r M o V 51\end{array}$ & 0 & 0 & 0 & 0 & 1.96 & 0.56 & 0 & 1 & 0.08 & 1 & $+\infty$ \\
\hline
\end{tabular}

Table 5: Ranking of solution technical optimality based on WFAD algorithm.

\begin{tabular}{clc}
\hline Place & \multicolumn{1}{c}{ Ranking based on IwFAD } & I $^{\text {WFAD }}$ \\
\hline & & STB \\
\hline $1^{\text {st }}$ & $\mathrm{CuBe}$ (Materion Alloy 165 temper TF00) & 1.05 \\
\hline $2^{\text {nd }}$ & $\mathrm{CuBe} 2$ & 2.52 \\
\hline $3^{\text {th }}$ & Alloy 310 (Materion Alloy 310 temper TF00) & 2.14 \\
\hline $4^{\text {th }}$ & Alloy 3 (Materion Alloy 3 temper TF00) & 3.22 \\
\hline N.A. & $\mathrm{C} 18150$ & $+\infty$ \\
\hline N.A. & $\mathrm{C} 18000$ & $+\infty$ \\
\hline N.A. & 50CrV4 (AISI 6150 steel oil quenched, 540 ${ }^{\circ} \mathrm{C}$ & $+\infty$ \\
\hline N.A. & tempering, D=50mm) & $+\infty$ \\
\hline N.A. & x38CrMoV51 (AISI Type H11) & $+\infty$ \\
\hline
\end{tabular}

Table 6: Ranking of solution technical optimality based on IAMS- C-VIKOR algorithm [17].

\begin{tabular}{clc}
\hline Place & \multicolumn{1}{c}{ Ranking based on $\mathbf{Q}_{\mathbf{i}}$} & $\mathbf{Q}_{\mathbf{i}}$ \\
\hline & & STB \\
\hline $1^{\text {st }}$ & CuBe2 & 0.00 \\
\hline $2^{\text {nd }}$ & CuBe (Materion Alloy 165 temper TF00) & 0.310 \\
\hline $3^{\text {th }}$ & Alloy 310 (Materion Alloy 310 temper TF00) & 0.372 \\
\hline $4^{\text {th }}$ & Alloy 3 (Materion Alloy 3 temper TF00) & 0.399 \\
\hline $5^{\text {th }}$ & C18150 & 0.815 \\
\hline $6^{\text {th }}$ & C18000 & 0.852 \\
\hline $7^{\text {th }}$ & $\begin{array}{l}\text { 50CrV4 (AISI 6150 steel oil quenched, 540 } \\
\text { tempering, D=50mm) }\end{array}$ & 0.935 \\
\hline $8^{\text {th }}$ & SS 410 martensitic stainless steel & 0.991 \\
\hline $9^{\text {th }}$ & $\mathrm{x} 38 \mathrm{CrMoV51} \mathrm{(AISI} \mathrm{Type} \mathrm{H11)}$ & 1.140 \\
\hline
\end{tabular}


By the comparison of the results coming from the application C-VIKOR and Fuzzy Axiomatic Design approaches (considering both FAD and WFAD approach) it is possible to observe several aspects:

- $\mathrm{C}-\mathrm{VIKOR}$ is able to produce a ranking with all the candidates, regardless of their ability to fulfill the requirements. The algorithm is able to discriminate between all of the various solutions;

- Fuzzy Axiomatic Design, using both FAD and WFAD, gives an indication only if the candidate is able to satisfy all the requirements in some way (i.e. the probability shall be never zero considering each of the selection attributes). Otherwise, the information content becomes $+\infty$ with even one criterion not met. From a practical standpoint, it means that Fuzzy Axiomatic Design algorithms are useful in defining what is the best solution among a pool of good candidates (optimization) but is not good in discerning among non-optimal and very bad candidates;

- For the candidates able to satisfy all the attributes, CVIKOR and Fuzzy Axiomatic Design give quite aligned results. 3

\section{CONCLUSION}

Summing up results obtained in this work, it is evident that the two algorithms have different behaviors.

C-VIKOR returns a complete ranking for all the candidates, allowing, on the one hand, to distinguish between the nonoptimal and the worst. On the other hand, C-VIKOR does not highlight the difference between the candidates that fulfill all the attributes and who is, in some cases, is out of design range.

FAD and WFAD approaches are exactly the opposite. Being based on the probability of satisfying the design specification, as soon as a candidate is out of design, the information content became $+\infty$. Therefore, it is impossible to distinguish between who has just one attribute out of design from who has many attributes out of design. On the other hand, it is immediate, with the Fuzzy Axiomatic Design, to see whether a candidate fulfills all the attributes or not.

In conclusion, Fuzzy Axiomatic Design can be effectively used in an optimization phase, when either non-optimal candidates have already been removed by the selection list or when the design ranges have been re-defined. C-VIKOR, on the contrary, can also be used in a screening phase, to define what are the worst choices and remove them from the next selection iterations.

When candidates are reasonable, C-VIKOR and Fuzzy Axiomatic Design demonstrated to give aligned results.

\section{ACKNOWLEDGMENT}

The author gratefully acknowledges the support of dr. Alessandro Bacigalupo for his work "Axiomatic Design: the information Axiom and the robustness index" (Bachelor
Thesis in Industrial Engineering, Guglielmo Marconi University, 2019) that gave an important reference for this paper.

\section{REFERENCE}

[1] A. Jahan, M. Bahraminasab, and K.L. Edwards, "A target-based normalization technique for materials selection”, Mat Des, vol.35, pp. 647-654, 2012.

[2] A. Mayyas, Q. Shen, A. Mayyas, M. Abdelhamid, D. Shan, A. Qattawi, and M. Omar, "Using Quality Function Deployment and Analytical Hierarchy Process for material selection of Body-In-White", Mat Des, vol.32, pp. 2771-2782, 2011.

[3] C. Cavallini, A. Giorgetti, P. Citti, and F. Nicolaie, "Integral aided method for material selection based on quality function deployment and comprehensive VIKOR algorithm", Mat Des, vol. 47, pp. 27-34, 2013.

[4] A. Jahan, K.L. Edwards, M. Bahraminasab, Multicriteria Decision Analysis For Supporting the Selection of Engineering Materials in Product Design, II edition, ed. Butterworth-Heinemann, 2016.

[5] A. Jahan, F. Mustapha, M.D. Ismail, S.M. Sapuan, and M. Bahraminasab, "A comprehensive VIKOR method for material selection", Mat Des; vol. 32, pp.12151221, 2011.

[6] N.P. Suh, Axiomatic Design: Advances and Applications, ed. Oxford University Press, New York 2001.

[7] G. Arcidiacono, D.T. Matt, E. Rauch, "Axiomatic Design of a Framework for the Comprehensive Optimization of Patient Flows in Hospitals", Journal of Healthcare Engineering, vol. 2017, Article ID 2309265, 9 pp., 2017.

[8] C. Monti, A. Giorgetti, and A. Girgenti, "An Axiomatic Design Approach for a Motorcycle Steering Damper". Procedia CIRP, vol. 34, pp. 150-155, 2015.

[9] A. Girgenti, B. Pacifici, A. Ciappi, and A. Giorgetti, "An Axiomatic Design Approach for Customer Satisfaction through a Lean Start-up Framework". Procedia CIRP, vol. 53, pp. 151-157, 2016.

[10] A. Giorgetti, A. Girgenti, P. Citti, and M. Delogu, "A novel approach for axiomatic-based design for the environment". In: Axiomatic design in large systems: Complex products, buildings and manufacturing systems, pp. 131-148, Springer, 2016.

[11] G. Arcidiacono, A. Giorgetti, A. Ciappi, "An Axiomatic Design framework for reliability improvement", ACM International Conference Proceeding Series, pp. 214-217, 2017

[12] G. Büyüközkan, F. Göçer, "Application of a new combined intuitionistic fuzzy MCDM approach based on axiomatic design methodology for the supplier selection problem", Applied Soft Computing, 52, 12221238, 2017.

[13] O. Kulak, C. Kahraman, "Fuzzy multi-attribute selection among transportation companies using Axiomatic Design and analytic hierarchy process", Information Sciences vol. 170, issues 2-4, 2005. 
[14] M. Karatas, "Multiattribute Decision Making Using Multiperiod Probabilistic Weighted Fuzzy Axiomatic Design", Systems Engineering, 2017.

[15] A. Kulak, "A decision support system for fuzzy multiattribute selection of material handling equipments", Expert Syst Appl, vol. 29, issue 2, 2005.

[16] O. Kulak, M.B. Durmusoglu, and C. Kahraman, "Fuzzy multiattribute equipment selection based on information axiom", J Mater Process Tech, vol. 169, 337-345, 2005.

[17] A. Giorgetti, C. Cavallini, A. Arcidiacono, and P. Citti, "A Mixed C-VIKOR Fuzzy Approach for Material Selection during Design Phase: A Case Study in Valve Seats for High Performance Engine", International Journal of Applied Engineering Research, vol. 12 issue 12: pp. 3117-3129, 2017.

[18] G. Arcidiacono, A. Pieroni, "The Revolution Lean Six Sigma 4.0, International Journal on Advanced Science, Engineering and Information Technology", vol. 8 issue 1, pp. 141-149, 2018.

[19] S. Badwe, T.E. Erkan, "A taxonomy of lean six sigma and agile methodologies used in software development", International Journal of Engineering Research and Technology, vol. 11, no. 5, pp. 725-754, 2018.

[20] T.O. Kehinde, A.E. Oluleye, K.J. Olaleye, S.L. Jegede, "Six sigma approach in safety management of a production firm", International Journal of Engineering Research and Technology, vol. 12, no. 10, pp. 16541663, 2019.

[21] G. Arcidiacono, E.W. De Luca, F. Fallucchi, A. Pieroni, "The use of Lean Six Sigma methodology in Digital Curation", CEUR Workshop Proceedings, Vol.1764, 2016. 